\title{
POLITICA ECONOMICA ARGENTINA. 1946-1983. CRONICA DE UNA CONFERENCIA
}

CARLOS RODRIGUEZ BRAUN

Entre los días 20 y 24 de mayo pasado se celebró en Toledo -en el Centro de Estudios San Juan de la Penitencia, de la Fundación Ortega y Gasset- la II Conferencia Internacional sobre Política Económica Argentina, organizada por el Instituto Di Tella, de Buenos Aires, y la referida Fundación. La Conferencia, que cubrió el período 1946 a 1983, tuvo dos características sobresalientes: por un lado, reunió a un calificado grupo de economistas de varios países y, por otro lado, contó con la presencia de algunas de las autoridades económicas que actuaron en Argentina durante dicho período.

Esta última característica dio a la Conferencia un brillo peculiar, puesto que la parte académica de la reunión se vio sumamente enriquecida por la aportación de quienes fueron protagonistas de las diferentes políticas económicas.

Tuvieron lugar siete sesiones, todas con el mismo esquema: en primer lugar, las ponencias $y$ los comentarios de carácter académico; en segundo lugar, las exposiciones de los ministros $v$ otras autoridades que hubiesen ejercido durante el periodo en cuestión y, finalmente, un debate general.

Las sesiones se desarrollaron de la forma siguiente:

I. Los dos primeros Gobiernos peronistas, 1946-1955, fueron objeto de las ponencias de Pablo Gerchunoff y Jorge Fodor. La tesis de Pablo Gerchunoff fue que no existió específicamente una política económica homogénea en aquellos años, y mucho menos una estrategia de crecimiento de largo plazo; independientemente de la retórica oficial -que a veces insistía en formular sus actos de gobierno como un «plan»- el objetivo prioritario, y en ocasiones excluyente, fue modificar velozmente la distribución del ingreso a favor de los trabajadores y luego restablecer el orden económico intentando mantener el nuevo patrón distributivo. Otro aspecto de importancia en la política económica peronista fue la notable expansión de la esfera de la economía bajo propiedad, control o intervención estatal. El peronismo alentó 
una revolución en las aspiraciones, que llevó a una inestabilidad: Gerchunoff concluyó que, en el segundo Gobierno, la autodisciplina social había permitido restablecer el orden y que, por lo tanto, se puede afirmar que el peronismo no fue derribado por razones de índole económica.

Jorge Fodor sostuvo que, aunque es frecuente que los Gobiernos echen sobre el pasado las culpas por los problemas económicos, tal actitud suele atenuarse tras un par de años; por el contrario, Perón era responsabilizado ante los problemas económicos argentinos aún diez años después de su derrocamiento. En opinión de Fodor, es un mito el que las acciones emprendidas en 1946-1948 hayan arruinado a la economía argentina; destacó, asimismo, que la política de Perón, poco conciliadora en las palabras, lo fue mucho más en los hechos.

Las exposiciones de Gerchunoff y Fodor recibieron los comentarios de Sir Alec Cairncross, Carlos Díaz Alejandro y Saturnino Aguado.

II. La segunda sesión se inició con una reseña de Peter Alhadeff sobre los años 1955-1958; su tesis fue que las políticas económicas de la revolución que derrocó a Perón no fueron muy diferentes a las que se habían aplicado en los últimos años del período peronista. El Gobierno provisional, en los hechos, renunció a efectuar grandes cambios en el manejo de los asuntos económicos y, así, la retirada del Estado de la economía no fue tan importante como pudo haber sido. Igual que con Perón, la economía estuvo fuertemente subordinada a la política. En resumen, las bases del desarrollo económico argentino no fueron puestas profundamente en cuestión.

A continuación, Alberto Petrecolla disertó sobre el período 1958-1962. A diferencia de casos anteriores, argumentó que durante estos años sí puede decirse que la política ejecutada estuvo marcada por el designio explícito y manifiesto de producir un cambio perdurable en la estructura económica argentina. Destacó Petrecolla que el sesgo antiexportador, introducido en la economía argentina durante la posguerra, fue acentuado por el tipo de inversiones estimuladas entre 1958 y 1962, puesto que las nuevas industrias tenían un tamaño mínimo que excedía marcadamente la extensión del mercado interno a precios internacionales, de donde se agudizaba el conflicto entre una política exportadora y la distribución del ingreso.

La ponencia de A. Petrecolla fue comentada por Albert O. Hirschmann y Domingo Cavallo. A continuación hicieron uso de la palabra dos ex ministros: Alvaro Alsogaray y Roberto Alemann.

III. En la tercera sesión, Juan Carlos de Pablo brindó una visión de los años 1962-1963; reivindicó el interés de un período poco estudiado 
por los especialistas $y$, además, poco valorado. De Pablo, que anotó la similitud de este caso con el de 1982-1983, sostuvo que la política económica recesiva de las autoridades había sido la correcta, dada la particular actitud del público que, por razones complementarias extra-económicas, no demandaba dinero.

Carlos García Tudero habló sobre el Gobierno radical de 1963-1966, destacando sus convicciones éticas y democráticas. Apuntó que la filosofía económica radical fue de dirigismo hacia el desarrollo y el progreso social, pero no de estatismo. Resaltó el elemento político - y la acción sindical empresarial- en el golpe militar de 1966, que derrocó al presidente Illia, a cuya memoria dedicó su exposición. Seguidamente, efectuaron comentarios Alieto Guadagni, Victoriano Martín y José Luis Machinea.

IV. Geoffrey Maynard disertó, en la cuarta sesión de esta Conferencia, sobre el período 1966-1973. El programa de estabilización del Gobierno del general Onganía -sostuvo- logró buenos resultados iniciales, pero afectó profundamente algunos mercados clave, como el de la carne -cuyos precios internacionales, además, cayeron-, y condujo, finalmente, a aumentos salariales en el sector público y al recrudecimiento de la inflación. Maynard puso énfasis en los problemas estructurales de la Argentina: un desarrollo industrial excesivamente protegidc, que castiga a la agricultura, pero que tampoco consiguè solidificar una industria internacionalmente competitiva.

Comentaron, a continuación, Juan Carlos Portantiero y León Benelbas. Hablaron, después, tres autoridades del período: José María Dagnino Pastore, Jorge Whebe y Alberto Solá.

V. La economía en el tercer Gobierno peronista, 1973-1976, fue el objeto de la ponencia de Guido Di Tella. Destacó el carácter faccionario del peronismo, más marcado que en otros partidos de base laboral. El Gobierno que asumió en 1973 tuvo fuertes oscilaciones políticas: el mismo partido en el Poder pasó de la extrema izquierda (Cámpora) a Perón, y de Perón a la extrema derecha (Isabel Perón), El programa económico peronista, argumentó Di Tella, marcado por el entorno de la crisis mundial, arrojó satisfactorios resultados iniciales, pero a finales de 1973 se volvió crecientemente incongruente: la tasa de inflación esperada era incompatible con la intensidad en la creación de dinero. El ajuste fue postergado, y cuando finalmente tuvo lugar fue más costoso, económicamente, y más conflictivo, socialmente - situación que se presentó también en otros países.

La exposición de Guido Di Tella fue seguidamente comentada por Walter Eltis y Juan José Camio. 
VI. La exposición correspondiente al período 1976-1981 corrió a cargo de Larry Sjaastad, quien sostuvo que, pese a lo que se dice, la política del Gobierno del general Videla no fue ni monetarista ni liberal; la imposibilidad de controlar el déficit fiscal socavó la credibilidad de dicha política y, finalmente, llevó a su liquidación durante 1981. Sjaastad se centró especialmente en la «tablita» - mecanismo que consideró válido- y apuntó el gran alza de los tipos de interés en la segunda mitad de 1979, y el surgimiento del temor ante una devaluación no programada. La «tablita» fue mantenida pese a la falta de confianza, y ello provocó la extensión de la descapitalización y el endeudamiento. Opinó Sjaastad que el Plan del 20 de diciembre no pudo atenuar más rápidamente la inflación porque abrió antes y más el mercado financiero que el de bienes. Resaltó, asimismo, el lado político, recordando cómo el prolongado silencio del general Viola, designado presidente en octubre de 1980, contribuyó mucho a la incertidumbre acerca de la continuidad del programa.

La exposición de Larry Sjaastad fue comentada por Franco Modigliani y por quien esto escribe. A continuación hizo uso de la palabra el ministro del período: José A. Martínez de Hoz.

VII. La última sesión, que cubrió los años 1981-1983, incluyó una ponencia de Rudiger Dornbusch. Tras diez años de crisis, expresó el conferenciante, no tiene mucho sentido buscar un responsable de la destrucción de la estabilidad social y económica; mientras Martínez de Hoz venció la inflación desplazando los costes de la sobrevaluación y de las deudas a Gobiernos posteriores, Dagnino Pastore y Cavallo dejaron mucha más inflación, pero redujeron las deudas privadas y públicas mediante tipos de interés reales negativos. Anotó, sin embargo, Dornbusch una consideración política: las autoridades que iniciaron su gestión con apoyo y credibilidad deben ser juzgadas más estrictamente. El mensaje final del ponente fue bastante pesimista: la situación que recibió Alfonsín en 1983 resultó peor que la que adquirió Videla siete años antes.

Las palabras de Dornbusch fueron comentadas por Yair Mundlak y Feliciano Hernández Iglesias. Intervinieron, seguidamente, cuatro autoridades del período: Roberto Alemann, José María Dagnino Pastore, Jorge Whebe y Domingo Cavallo.

Todas las sesiones y sus correspondientes debates, que llenaron un animado y apretado programa de trabajo de tres días y medio, se desarrollaron en un marco de gran tolerancia y respeto mutuo; considerando la conflictividad y cercanía de los períodos analizados y la diversidad de los puntos de vista de los participantes, ello puede mencionarse como uno de los aspectos más sobresalientes del encuentro. Hubo un acuerdo general: habría sido muy 
difícil, si no imposible, celebrar una reunión de estas características en Argentina...

La Conferencia fue inaugurada y cerrada con la intervención de dona Soledad Ortega, presidenta de la Fundación Ortega y Gasset, quien dirigió cálidas palabras a los asistentes y recordó la simpatía y atención que siempre dispensó a la Argentina el gran filósofo español. Simpatía y atención fueron también las características de los economistas y autoridades políticas y académicas de España, que fueron invitados a participar en la Conferencia, efectuando comentarios a las diversas ponencias, y presidiendo y moderando las sesiones.

En resumen, una reunión del máximo interés, cuyo contenido será próximamente publicado en inglés y en castellano -habrá, probablemente, un volumen especial dedicado con exclusividad a las autoridades y que incluirá a quienes no pudieron asistir a la Conferencia - y que constituirá, sin duda, un documento de significativa relevancia para la comprensión de la historia económica argentina en el siglo $\mathbf{x x}$. 